\title{
Measuring myocardium at risk in acute myocardial infarction-A continuing challenge
}

\author{
Todd D. Miller, MD, and Raymond J. Gibbons, MD
}

\section{See related article, pp. 825-830}

In patients with acute myocardial infarction (AMI) with ST elevation, early reperfusion therapy with either direct percutaneous coronary intervention ${ }^{1}$ or thrombolytic agents ${ }^{2}$ significantly reduces mortality. The decline in mortality is partially related to a reduction in infarct size. Myocardial perfusion imaging can be utilized in these patients to measure both myocardium at risk (MAR) when a patient first arrives in the emergency department and final infarct size several days later. The difference between MAR and final infarct size represents "myocardial salvage." Dividing the amount of myocardial salvage by the amount of MAR provides a "salvage index.",

Early studies in the 1980s that measured infarct size and myocardial salvage used thallium (Tl)-201.,4 The subsequent introduction of technetium (Tc)-based perfusion radioisotopes facilitated this process, especially for measuring MAR. In contrast to Tl-201, Tc-99m undergoes minimal redistribution over time, ${ }^{5,6}$ permitting a delayed image acquisition several hours after injection, and after administration of reperfusion therapy, that still reflects myocardial perfusion at the time of injection in the emergency department. Another advantage of Tc-99m over Tl-201 is its higher peak energy window, which permits more accurate identification of the boundaries of a perfusion defect ${ }^{7,8}$ and increases the accuracy of gated images.

Infarct size and myocardial salvage have been extensively validated as surrogate endpoints for mortality in the setting of AMI. ${ }^{9,10}$ Although these measurements are not routinely made clinically, they have been applied as endpoints in over 30 AMI trials comparing different therapeutic strategies or examining the efficacy of novel

From the Mayo Clinic, Rochester, MN.

Reprint requests: Todd D. Miller, MD, Mayo Clinic, 200 First Street

S.W., Rochester, MN 55905; miller.todd@mayo.edu.

J Nucl Cardiol 2010;17:778-80.

$1071-3581 / \$ 34.00$

Copyright $@ 2010$ American Society of Nuclear Cardiology.

doi:10.1007/s12350-010-9278-3 agents or devices. ${ }^{11}$ Infarct size alone has been used as the endpoint in the majority of these trials, and particularly the more recent ones, since it is logistically easier. Patients only need to undergo one imaging study more than 120 hours (5 days) after reperfusion therapy when they are clinically stable. In contrast, the measurement of myocardial salvage requires an early imaging study to determine MAR. Although the intravenous injection of a dose of Tc-99m sestamibi in the emergency department is not difficult, a supply of Tc-99m sestamibi must be readily available (the isotope must be prepared every 6 hours by a technologist to comply with the package insert), and imaging needs to generally be performed within 6 hours of injection. Many hospitals have been unable to meet these requirements.

What are the advantages of measuring myocardial salvage rather than measuring infarct size alone? The use of myocardial salvage rather than infarct size as an endpoint in clinical trials should permit a smaller patient sample size. However, the difference in sample size is more modest than expected, as each parameter has a similar relationship between its variability (expressed as the standard deviation) and the expected difference with treatment. $^{12}$ As a result, several positive clinical trials have reported similar results for both myocardial salvage and infarct size. ${ }^{13,14}$ The gain in statistical power with the measurement of MAR is best achieved with an analysis of covariance. $^{12}$

Another advantage of measuring salvage is the insight that it provides into treatment efficacy in an individual patient. Studies in animals ${ }^{15}$ and humans ${ }^{16}$ have demonstrated that the amount of MAR can vary widely, even for a coronary artery occlusion in the same territory. Two patients may both have final infarct size of $20 \%$, but in one patient MAR may have been $60 \%$, whereas in the other patient MAR may have been $20 \%$. Measuring salvage provides knowledge of treatment efficacy in these two patients that would not be available from measurement of infarct size alone.

In this issue of the Journal, Sciagra et $\mathrm{al}^{17}$ describe a novel approach for the measurement of MAR. These investigators take advantage of the concept of myocardial stunning to estimate MAR from the extent of myocardium with impaired regional wall thickening on a gated SPECT Tc-99m sestamibi image performed at an average of 5 days post-AMI. In 36 patients with first 
AMI treated within 6 hours by primary percutaneous coronary intervention, there was a close correlation (Spearman's $\rho=.92, P<.0001$ ) between the new "thickening" salvage index and the conventionally performed "perfusion" salvage index obtained from standard acute and delayed images. A rigorous BlandAltman analysis showed that the $95 \%$ limit of agreement between the two salvage indices was \pm .25 . Both indices were significantly associated (univariable analysis) with 1-month follow-up gated SPECT left ventricular ejection fraction.

These provocative results suggest that myocardial salvage can potentially be measured by acquiring a simple, "one-stop-shop" delayed gated SPECT image in place of the more difficult approach that depends on the acquisition of both acute and delayed perfusion images.

The study of Sciagra et $\mathrm{al}^{17}$ does have limitations. As acknowledged by the authors, their sample size was small. The regional perfusion and wall thickening images were interpreted subjectively by a single observer rather than applying a quantitative threshold technique, which has been used in most studies to measure infarct size and myocardial salvage. ${ }^{11}$ Such subjective measurements are usually associated with greater variability, and therefore require a larger sample size in clinical trials. Patient misclassification may potentially off-set any reduction in sample size achieved by measuring salvage rather than infarct size alone. In this study the misclassification rate applying the thickening salvage index in place of the perfusion salvage index was $17 \%$ (6/36). Finally, the optimal timing of acquiring the single gated SPECT image is unknown. In this study imaging was performed at an average of 5 days with a range of 2-8 days. Previous work from our laboratory cited by Sciagra et al $^{17}$ indicated that measurement of infarct size at 48 hours would over-estimate infarct size in some patients. ${ }^{18}$ Unfortunately, myocardial stunning has already started to resolve at that time in some patients. ${ }^{19}$ The optimal timing for a single gated SPECT image is therefore likely to differ between patients.

Despite these limitations, the novel approach developed by Sciagra et al is commendable, and merits further investigation. Future studies will hopefully address the issues of quantitation, misclassification, and timing, and provide comparisons to magnetic resonance imaging (MRI). MRI is another imaging modality that is being increasingly utilized to measure infarct size. ${ }^{20,21}$ Although MRI can detect smaller infarctions and is more reproducible, this does not necessarily translate into an advantage as an endpoint in clinical trials. ${ }^{10}$ Two comparative studies have reported similar infarct sizes and standard deviations using MRI and SPECT, ${ }^{22,23}$ which would imply similar required sample sizes for both approaches. An emerging literature has also investigated the ability of MRI to measure MAR in a delayed timeframe by identifying myocardial edema. ${ }^{24-26}$ These efforts with MRI, as well as the current paper by Sciagra et al, reflect ongoing interest in developing a method to accurately measure MAR (and myocardial salvage) in a delayed, logistically simple manner that does not interfere with the administration of reperfusion therapy. However, these approaches require more extensive validation before they can be applied with confidence as endpoints in clinical trials.

\section{References}

1. Keeley EC, Boura JA, Grines CL. Primary angioplasty versus intravenous thrombolytic therapy for acute myocardial infarction: A quantitative review of 23 randomised trials. Lancet 2003;361: 13-20.

2. Fibrinolytic Therapy Trialists' (FTT) Collaborative Group. Indications for fibrinolytic therapy in suspected acute myocardial infarction: Collaborative overview of early mortality and major morbidity results from all randomised trials of more than 1000 patients. Lancet 1994;343:311-22.

3. Ritchie JL, Davis KB, Williams DL, Caldwell J, Kennedy JW. Global and regional left ventricular function and tomographic radionuclide perfusion: The Western Washington Intracoronary Streptokinase in Myocardial Infarction Trial. Circulation 1984;70: 867-75.

4. DeCoster PM, et al. Coronary artery reperfusion in acute myocardial infarction: Assessment by pre- and post-intervention thallium-201 myocardial perfusion imaging. Am J Cardiol 1985;55: 889-95.

5. Okada RD, Glover D, Gaffney T, Williams S. Myocardial kinetics of technetium-99m-hexakis-2-methoxy-2-methylpropyl-isonitrile. Circulation 1988;77(2):491-8.

6. Taillefer R, Primeau M, Costi P, Lambert R, Leveille J, Latour Y. Technetium-99m sestamibi myocardial perfusion imaging in detection of coronary artery disease: Comparison between initial (1-hour) and delayed (3-hour) postexercise images. J Nucl Med 1991;32:1961-5.

7. O'Connor MK, Caiati C, Christian TF, Gibbons RJ. Effects of scatter correction on the measurement of infarct size from SPECT cardiac phantom studies. J Nucl Med 1995;36:2080-6.

8. Kailasnath P, Sinusas AJ. Comparison of Tl-201 with Tc-99mlabeled myocardial perfusion agents: Technical, physiologic, and clinical issues. J Nucl Cardiol 2001;8:482-98.

9. Gibbons RJ, Miller TD, Christian TF. Infarct size measured by single photon emission computed tomographic imaging with 99 mTc-sestamibi-a measure of the efficacy of therapy in acute myocardial infarction. Circulation 2000;101:101-8.

10. Gibbons RJ, Valeti US, Araoz PA, Jaffe AS. The quantification of infarct size. J Am Coll Cardiol 2004;44:1533-42.

11. Miller TD, Sciagra R, Gibbons RJ. Application of technetium-99m sestamibi single photon emission computed tomography in acute myocardial infarction: Measuring the efficacy of therapy. Q J Nucl Med Mol Imaging 2010;54:213-29.

12. Gibbons RJ, Christian TF, Hopfenspirger MR, Hodge DO, Bailey KR. Myocardium at risk and infarct size after thrombolytic therapy for acute myocardial infarction: Implications for the design of randomized trials of acute intervention. J Am Coll Cardiol 1994; 24:616-23. 
13. Schaer GL, Spaccavento LJ, Browne KF, Krueger KA, Krichbaum D, Phelan JM, Fletcher WO, Grines CL, Edwards S, Jolly MK, Gibbons RJ. Beneficial effects of RheothRx injection in patients receiving thrombolytic therapy for acute myocardial infarction. Results of a randomized, double-blind, placebo-controlled trial. Circulation 1996;94:298-307.

14. Schomig A, Kastrati A, Dirschinger J, Mehilli J, Schricke U, Pache J, Martinoff S, Neumann FJ, Schwaiger M. Stent versus thrombolysis for occluded coronary arteries in patients with acute myocardial infarction study investigators. Coronary stenting plus platelet glycoprotein IIb/IIIa blockade compared with tissue plasminogen activator in acute myocardial infarction. $\mathrm{N}$ Engl $\mathrm{J}$ Med 2000;343:385-91.

15. Reimer KA, Ideker RE, Jennings RB. Effect of coronary occlusion site on ischemic bed size and collateral blood flow in dogs. Cardiovasc Res 1981;15:668-74.

16. Feiring AJ, Johnson MR, Kioschos JM, Kirchner PT, Marcus ML, White CW. The importance of the determination of the myocardial area at risk in the evaluation of the outcome of acute myocardial infarction in patients. Circulation 1987;75:980-7.

17. Sciagrà R, Dona M, Coppola $\mathrm{A}$, Leoncini M, Maioli M, Castagnoli A, et al. Feasibility of an accurate assessment of myocardial salvage by comparing functional and perfusion abnormalities in postreperfusion gated SPECT. J Nucl Cardiol 2010. doi:10.1007/ s12350-010-9247-x.

18. Pellikka PA, Behrenbeck T, Verani MS, Mahmarian JJ, Wackers FJ, Gibbons RJ. Serial changes in myocardial perfusion using tomographic technetium-99m-hexakis-2-methoxy-2-methylpropylisonitrile imaging following reperfusion therapy of myocardial infarction. J Nucl Med 1990;31:1269-75.

19. Oh JK, Gibbons RJ, Christian TF, Gersh BJ, Click RL, Sitthisook S, Tajik AJ, Seward JB. Correlation of regional wall motion abnormalities detected by two-dimensional echocardiography with perfusion defect determined by technetium $99 \mathrm{~m}$ sestamibi imaging in patients treated with reperfusion therapy during acute myocardial infarction. Am Heart J 1996;131:32-7.

20. Kim RJ, Fieno DS, Parrish TB. Relationship of MRI delayed contrast enhancement to irreversible injury, infarct age, and contractile function. Circulation 1999;100:1992-2002.

21. Kim RJ, Wu E, Rafael A. The use of contrast-enhanced magnetic resonance imaging to identify reversible myocardial dysfunction. N Engl J Med 2000;343:1445-53.

22. Mahrholdt H, Wagner A, Holly TA, Elliott MD, Bonow RO, Kim RJ, Judd RM. Reproducibility of chronic infarct size measurement by contrast-enhanced magnetic resonance imaging. Circulation 2002;106:2322-7.

23. Ibrahim T, Nekolla SG, Hornke M, Bulow HP, Dirschinger J, Schomig A, Schwaiger M. Quantitative measurement of infarct size by contrast-enhanced magnetic resonance imaging early after acute myocardial infarction: Comparison with single-photon emission tomography using Tc99m-sestamibi. J Am Coll Cardiol 2005;45:544-52.

24. Aletras AH, Tilak GS, Natanzon A, Hsu LY, Gonzalez FM, Hoyt $\mathrm{RF} \mathrm{Jr}$, Arai AE. Retrospective determination of the area at risk for reperfused acute myocardial infarction with $\mathrm{T} 2$-weighted cardiac magnetic resonance imaging: Histopathological and displacement encoding with stimulated echoes (DENSE) functional validations. Circulation 2006;113:1821-3.

25. Friedrich MG, Abdel-Aty H, Taylor A, Schulz-Menger J, Messroghli D, Dietz R. The salvaged area at risk in reperfused acute myocardial infarction as visualized by cardiovascular magnetic resonance. J Am Coll Cardiol 2008;51:1581-7.

26. Carlsson M, Ubachs J, Hedstrom E, Heiberg E, Jovinge S, Arheden H. Myocardium at risk after acute infarction in humans on cardiac magnetic resonance. J Am Coll Cardiol Cardiovasc Imaging 2009;2:569-76. 